\title{
Sleepiness at the time of testing impairs olfactory performance
}

Ghielmini, E ; Poryazova, R ; Baumann, C R ; Bassetti, C L

DOI: https://doi.org/10.1159/000337449

Posted at the Zurich Open Repository and Archive, University of Zurich ZORA URL: https://doi.org/10.5167/uzh-67162

Journal Article

Published Version

Originally published at:

Ghielmini, E; Poryazova, R; Baumann, C R; Bassetti, C L (2013). Sleepiness at the time of testing impairs olfactory performance. European Neurology, 69(1):58-64.

DOI: https://doi.org/10.1159/000337449 


\title{
Original Paper
}

European

Neurology
Eur Neurol 2013;69:58-64

DOI: $\underline{10.1159 / 000337449}$
Received: December 9, 2011

Accepted: January 29, 2012

Published online: November 7, 2012

\section{Sleepiness at the Time of Testing Impairs Olfactory Performance}

\author{
Enea Ghielmini ${ }^{a}$ Rositsa Poryazova ${ }^{\mathrm{a}}$ Christian R. Baumann ${ }^{\mathrm{a}}$ \\ Claudio L. Bassettia, b \\ ${ }^{a}$ Department of Neurology, University Hospital Zurich, Zurich, and ${ }^{b}$ Neurocenter (EOC) of Southern Switzerland, \\ Neurology Department, Ospedale Civico, Lugano, Switzerland
}

\section{Key Words}

Olfactory function • Parkinson's disease $\cdot$ Narcolepsy

Restless legs syndrome $\cdot$ Excessive daytime sleepiness founding factor in the assessment of olfaction, e.g. in NC. Furthermore, our results confirm that olfaction is impaired in $\mathrm{PD}$, whereas it is normal in RLS.

Copyright $\odot 2012$ S. Karger AG, Basel

\begin{abstract}
Background: We aimed to investigate the differential roles of hypocretin versus dopamine dysfunction versus excessive daytime sleepiness (EDS) in the development of hyposmia. Olfaction in patients with Parkinson disease, restless leg syndrome, narcolepsy with cataplexy, EDS, and healthy controls was compared. Methods: Sixty-six subjects participated in the study: 14 with PD, 13 with NC, 12 with RLS, 8 with EDS, and 20 healthy controls. Olfaction was tested using standardized Sniffin'Sticks test. Sleepiness was assessed using Karolinska, Stanford and Epworth sleepiness scales. Results: Olfactory discrimination correlated negatively with subjective momentary sleepiness. A significant deficit in olfaction was found in PD patients with respect to all other groups in all olfactory domains. No significant differences were found between the other groups. Conclusion: We could not confirm decreased olfaction in patients with NC. Yet the significant correlation between momentary sleepiness and olfactory function suggests that sleepiness is a potential con-
\end{abstract}

\section{Introduction}

Olfactory deficit is a well-known early symptom of Parkinson disease (PD) [1]. REM sleep behavior disorder (RBD), which often precedes the clinical presentation of $\mathrm{PD}$ and other neurodegenerative disorders [2,3], has also been associated with hyposmia $[4,5]$. This is explained by the observations that during the premotor stages of PD neuropathological lesions initially occur in the anterior olfactory nucleus and the dorsal motor nucleus of the glossopharyngeal and vagal nerves, followed by lesions in the pontine tegmentum, including the coeruleus-subcoeruleus complex and the pedunculopontine nucleus $[6,7]$.

Decreased olfactory threshold has recently been described in narcolepsy patients with and without RBD [810]. In the largest and most recent study of olfactory function in narcolepsy [10], olfactory deficit in narcolepsy pa-

\section{KARGER \\ Fax +4161306 1234 E-Mail karger@karger.ch} www.karger.com

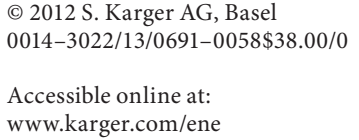

Claudio L. Bassetti, MD

Department of Neurology

University Hospital (Inselspital)

CH-3010 Bern (Switerland)

E-Mail claudio.bassetti@insel.ch 
Table 1. Demographic characteristics, KSS and ESS scores of the subjects

\begin{tabular}{|c|c|c|c|c|c|c|}
\hline & $\mathrm{n}$ & $\mathrm{M} / \mathrm{F}$ & $\begin{array}{l}\text { Mean age } \pm S D \\
\text { years }\end{array}$ & $\begin{array}{l}\text { Range } \\
\text { years }\end{array}$ & $\mathrm{KSS} \pm \mathrm{SD}$ & $\mathrm{ESS} \pm \mathrm{SD}$ \\
\hline $\mathrm{PD}$ & 13 & $8 / 5$ & $61.5 \pm 6.7$ & $52-73$ & $4.3 \pm 2.4$ & $7.92 \pm 4.79$ \\
\hline $\mathrm{NC}$ & 13 & $8 / 5$ & $45.9 \pm 14.9$ & $22-65$ & $3.6 \pm 2.5$ & $14.15 \pm 4.08$ \\
\hline RLS & 12 & $4 / 8$ & $50.2 \pm 18.6$ & $24-81$ & $3.1 \pm 2.3$ & $5.82 \pm 4.4$ \\
\hline EDS & 8 & $7 / 1$ & $46.7 \pm 17.3$ & $19-72$ & $6.1 \pm 2.3$ & $14.78 \pm 3.03$ \\
\hline Controls & 20 & $8 / 12$ & $52.5 \pm 16.6$ & $24-76$ & $2.3 \pm 1.6$ & $6.61 \pm 3.47$ \\
\hline
\end{tabular}

tients was mild to moderate and present in about a quarter of subjects.

Narcolepsy-cataplexy (NC) is a disabling life-long sleep-wake disorder, characterized by excessive daytime sleepiness (EDS) and sudden loss of muscle tone triggered by emotions (cataplexy) [11]. It is tightly associated with the loss of hypocretin (also called orexin) neurons in the posterior hypothalamus [12-14]. Hypocretin is a hypothalamic neuropeptide, involved in sleep-wake regulation, motor function, and food intake [15]. The hypocretin ligands and their receptors, except in the hypothalamus, are present at all levels of the olfactory system [16, 17]. It has been suggested that hypocretin increases olfactory sensitivity in rats [18] and its loss causes olfactory dysfunction in patients with NC [19]. A degeneration of the hypocretin olfactory nasal mucosa cells in NC patients was assumed and thought to support the hypothesis that narcolepsy is a neurodegenerative disease [8]. This assumption, however, has not been confirmed in autopsy studies.

Partial hypothalamic hypocretin cell loss was also reported in patients with PD [20,21]. It was suggested that this partial loss might contribute to EDS in PD.

Dopamine dysfunction is probably also relevant in restless legs syndrome (RLS), a sleep-related movement disorder. Similar to PD, decreased dopamine activity was shown in PET studies [22, 23]. In addition, the disorder responds very well to dopaminergic medication. So far, two studies examined olfactory function in RLS patients, showing normal results $[24,25]$.

Together with these neurotransmitter systems, vigilance, attention and sleep are important contributors for perception including olfaction. It has been shown that smell identification performance worsens after sleep deprivation [26]. Furthermore olfactory event-related potentials have a circadian rhythm opposite to sleepiness [27], and selective olfactory stimuli do not lead to arousals during nocturnal sleep $[28,29]$. The possible associa- tion between EDS and olfaction has not yet been examined.

Thus, is hyposmia due to dopamine or hypocretin dysfunction? Does sleepiness influence olfaction?

With this study, we wanted to test for olfaction deficits in patients with dopamine and/or hypocretin dysfunction. We hypothesized that decreased olfaction in $\mathrm{NC}$ and EDS patients might be partially due to sleepiness-associated attention and concentration impairment.

\section{Subjects and Methods}

To test our hypothesis, we analyzed olfaction and sleepiness in patients with NC, PD, RLS, EDS not caused by narcolepsy, and healthy control subjects.

The study was approved by the local ethics committee and all subjects provided written informed consent.

Patient Characteristics (table 1)

We examined 13 patients with PD, 13 patients with NC, 12 patients with RLS, 8 patients with EDS, and 20 control subjects.

Patients with PD were diagnosed according to the Queen Square British Brain Bank Criteria [30] and only patients with a Hoehn and Yahr score $\leq$ III were included. NC and RLS were diagnosed according to the International Classification of Sleep Disorders, second Edition, ICSD-2 [31]. All narcolepsy subjects also suffered from typical cataplexy, tested positive for HLA DQB1*0602 and had hypocretin (orexin) levels in the cerebrospinal fluid (CSF) either undetectable or low (measured in all but one patient). The EDS group was composed of patients with different disorders such as obstructive sleep apnea syndrome (SAS) $(n=2)$, behaviorally induced insufficient sleep syndrome $(n=4)$ and unclear causes of sleepiness $(n=2)$. All patients with EDS had ESS scores $\geq 10$ and a MSL $<8$ min. MSL was tested in all but one EDS patients.

Control subjects were screened for sleep-wake disorders using extensive sleep-questionnaires, excluding RLS, EDS, insomnia, possible OSAS, and parasomnias. Subjects with sleep-wake disorders were excluded.

General exclusion criteria for both patients and control subjects included cognitive impairment, gestation, upper airways infections, active allergic diseases of the upper airways, and recent 
use of upper airway medications. Smoking was not among the exclusion criteria since it was not proven to significantly affect olfaction $[10,32]$ (as confirmed by our results).

Drug therapy: Nine patients with PD were treated with levodopa with or without additional dopamine agonists, four received no dopaminergic medication. Four RLS patients were treated with dopaminergic agents, and 8 were untreated. Dopaminergic medication taken by PD and RLS patients was converted into dopamine equivalents.

Ten NC patients received treatment for EDS including sodium oxybate, modafinil, methylphenidate, or combinations. Two patients were also treated with venlafaxin.

\section{Olfactory Testing}

Olfaction was tested using Sniffin'Sticks, a standardized test already used in previous studies $[8,10]$. Subjects were tested during daytime by the two first authors in a regularly ventilated, closed room of neutral smell. A gap of at least $1 \mathrm{~h}$ was observed between the time points of testing and of last food intake.

Sniffin'Sticks are felt-tip pens filled with odorants in different concentrations. The test is composed of three parts, testing for olfactory threshold, discrimination, and identification. Subjects were blindfolded during testing. Each test was performed first bilaterally, then separately on the left and right nostril.

The test for threshold consists of 16 triplets of sticks. In each triplet one stick holds a specific concentration of N-butanol, dissolved in polypropylene glycol, whereas the other two are filled with solvent. N-butanol concentration decreases from stick number 1 to stick number 16 . Sticks with and without odorant are continuously presented to the subject in random order, but following an increasing or decreasing odor concentration staircase. Failure to recognize the odorant during decreasing concentration, as well as double recognition during increasing concentration leads to an inversion of the staircase. The average of the last four of eight staircase inversions was used as the final value.

The test for discrimination consists of 16 triplets of sticks, each of which contains two sticks with the same odor and one that is different. The subject must recognize which stick smells differently. The number of correctly evaluated triplets gives the discrimination score.

The test for identification consists also of 16 sticks containing different familiar odors to be identified, namely orange, leather, cinnamon, peppermint, banana, lemon, liquorice, turpentine, garlic, coffee, apple, clover, pineapple, rose, aniseed, and fish. The subject must identify the odor from a multiple choice of four possibilities per odor. The number of correct identifications gives the identification score.

The sum of the scores of the three sections in the Sniffin'Sticks test is called the Threshold-Discrimination-Identification sum score, or TDI score, which gives a general parameter for olfactory function in one subject and was used in previous studies.

\section{Assessment of Sleepiness and Attention}

Sleepiness and sleep characteristics were assessed using subjective and objective methods. Subjective momentary sleepiness was assessed for all subjects by using two different questionnaires: the Karolinska sleepiness scale (KSS [33]), and the Stanford sleepiness scale (SSS [34]), which describe increasing degrees of sleepiness respectively from 1 to 9 and from 1 to 7. Subjective EDS was assessed using the Epworth sleepiness scale (ESS), which mea-

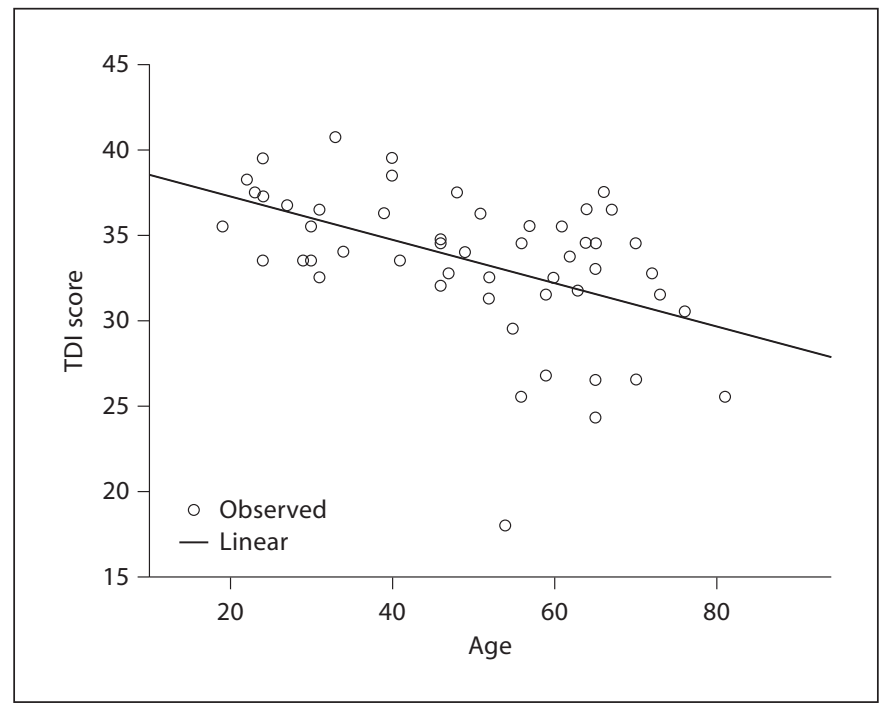

Fig. 1. Observed TDI scores depend on age in linear manner. PD patients are excluded.

sures the estimated likelihood of falling asleep during specific daily activities over the last four weeks. Scores above 10/24 indicate EDS.

A subset of patients with $\mathrm{NC}$ and EDS underwent multiple sleep latency tests (MSLT), which objectively measure momentary EDS.

Since attention may have an influence on olfaction performance, 34 patients and controls were tested for attention using the $\mathrm{d} 2$ test of attention. In this 4 '20" test, subjects must check as many marked 'd's as possible on a piece of paper. The number of checked letters and the number of mistakes allows objectifying the momentary attention of the subject.

\section{Statistics}

Quantitative data and graphics are presented as mean \pm SD. Comparison of means was performed using one-way ANOVA. Multiple comparison post-hoc tests were adjusted with the Bonferroni formula. In order to analyze data independently from the major confounding factor age, we created a second set of data adjusting the test scores for age using a linear regression that was calculated on data from all groups except PD patients. As hyposmia is a well-known disease dependent symptom in $\mathrm{PD}$, data from this group would have distorted the adjustment. The age dependent decay of olfactory performance has already been described as a mainly linear process $[25,35]$, whereas others [35] found that such decline is slightly increased with older age. Our data suggested a linear regression throughout the curve as suggested by the graph in figure 1 , and scores were adjusted consequently. The adjusted scores are the addition of the tested score and the regression coefficient multiplied by the subject's age. The calculated coefficients were 0.127 for the TDI score, 0.035 for threshold, 0.06 for discrimination, and 0.032 for identification. Correlations were calculated using bivariate Pearsons's Correlation. We excluded PD patients from all statistical testing except direct group comparisons. 

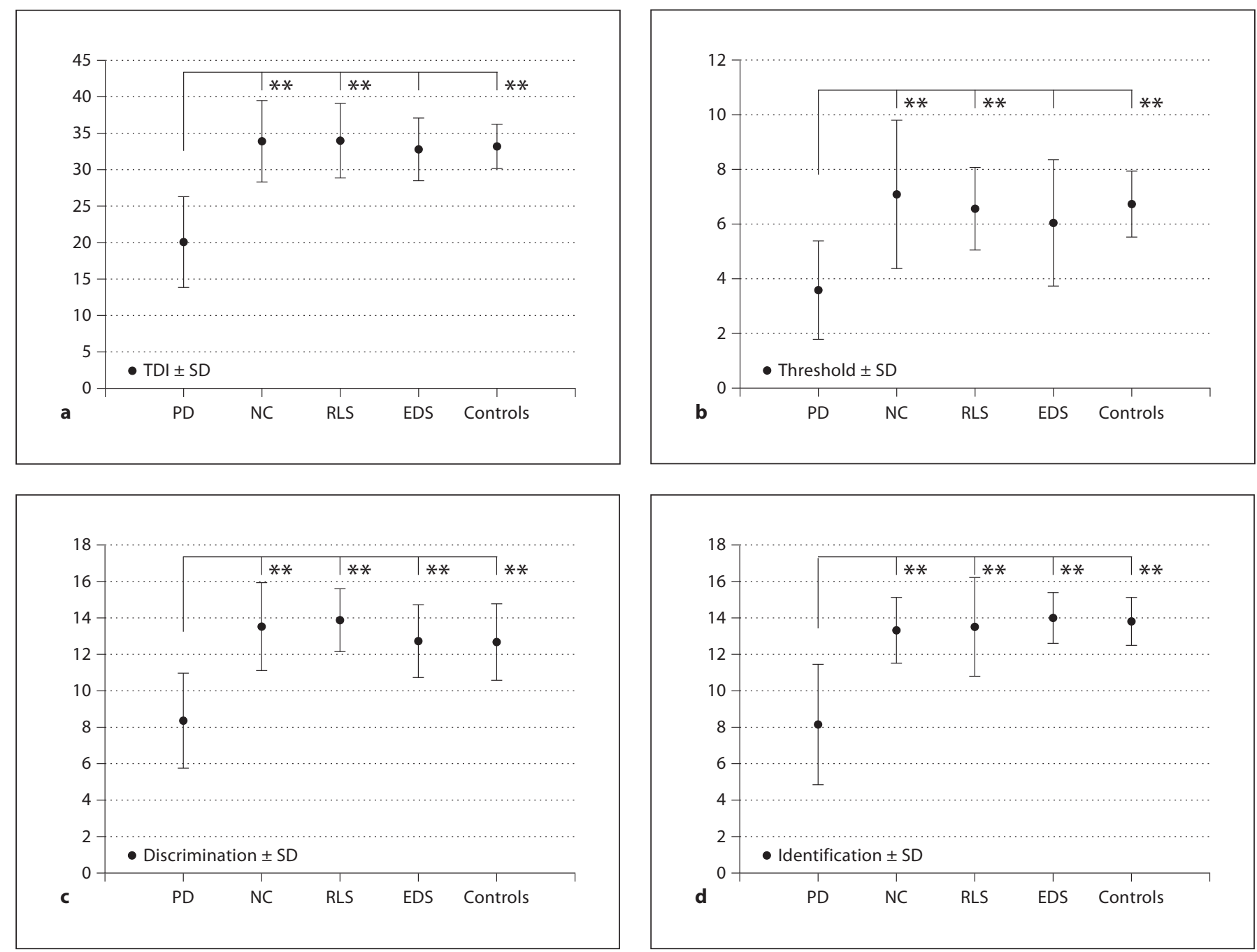

Fig. 2. a-d Mean TDI and subtest scores divided by groups. PD patients score significantly lower test resuls. Significant differences are indicated by asterisks.

\section{Results}

\section{Comparison of Groups}

We found an inverse correlation between age and olfactory test results $(\mathrm{r}=-0.497$ for the TSI score, -0.294 for threshold, -0.486 for discrimination, -0.239 for identification; $\mathrm{p}<0.05)$. Thus we adjusted for age as described above before performing further statistical analyses. Figure 2 shows the mean test results for the different subject groups before adjustment. One-way ANOVA testing before adjustment showed a significant difference between PD patients and all other groups in all three sections of olfaction testing and the TDI sumscore $(\mathrm{p}<0.001)$. When applying Bonferroni's correc- tion to multiple comparisons post-hoc test, the differences remained significant for all tests except for threshold and TDI score between the PD and EDS groups ( $\mathrm{p}=$ 0.46 and 0.272 ). Differences in discrimination and identification remained significant. No significant difference was found between patients with narcolepsy, RLS, EDS and healthy controls.

\section{Sleepiness and Olfaction}

We found significant correlations between subjective momentary sleepiness and the TSI score. The TSI score correlated negatively to the SSS score $(r=-0.37, \mathrm{p}=0.004)$ and to the KSS score $(r=-0.359, p=0.004)$. The scores for the discrimination sub-test also correlated to momen- 
tary sleepiness $(\mathrm{r}=-0.366, \mathrm{p}=0.008$ for SSS; $\mathrm{r}=-0.310$, $\mathrm{p}=0.027$ for KSS). Similar results concerning long-term daytime sleepiness (ESS) as well as correlations between threshold or identification testing and momentary sleepiness did not reach statistical significance.

Whereas both ESS and NC groups showed an increased general sleepiness score (ESS, $p<0.001$ ), only the EDS group also showed a significantly higher momentary sleepiness (KSS, $p=0.002$ ) compared to controls. See table 1 for mean sleepiness results.

Within the narcolepsy group, three of thirteen patients were not treated with stimulants or sodium oxybate. In comparison to the treated patients, this subgroup showed not only elevated mean sleepiness scores (SSS 4.3 vs. 1.4, KSS 6.6 vs. 2.7, ESS 17.7 vs. 13.1), but also reduced mean olfactory scores (threshold 6.8 vs. 9.2, discrimination 15.1 vs. 16.7 , identification 12.5 vs. 15.5 ).

\section{Olfaction and Other Factors}

Since marked asymmetry of the symptoms is a hallmark of PD, we compared olfaction scores between ipsiand contralateral nostrils using the paired sample t test, but we found no difference.

In the control group, as well as in all patients' groups olfaction did not depend on smoking, gender, or self estimated olfactory capability.

Levodopa-equivalent dose in PD and RLS patients did not correlate with olfactory performance.

The number of checked ' $\mathrm{d}$ ' on the $\mathrm{d} 2$ test correlated negatively with age $(r=-0.729, p<0.001)$, while no direct correlation was found between attention and olfaction once data were adjusted for age.

\section{Discussion}

There are three main findings of our systematic, prospective, controlled single-center study. The first is a negative correlation between momentary sleepiness and olfactory performance. The second is the confirmation of decreased, respectively normal olfaction in patients with $\mathrm{PD}$ and RLS. The third is the inability to confirm hyposmia for patients with $\mathrm{NC}$ in comparison to healthy controls.

Following the hypothesis that sleepiness might impair olfactory function, we analyzed the impact of sleepiness on olfactory test results. Our findings confirmed our hypothesis, most importantly the presence of significant correlations between subjective momentary sleepiness and discrimination testing. In the same direc- tion we found better testing scores for olfaction in treated compared to untreated NC patients who were also sleepier.

Like ours, the largest previous study on olfaction in NC using Sniffin'Sticks [10] showed significantly different scores only in the discrimination subtest, which may be the subtest requiring most attention and concentration, and therefore the first to be influenced by sleepiness. We could not show an association between olfactory performance and attention using $\mathrm{d} 2$ test of attention. However, others found that odor identification ability positively predicts performance on the Wisconsin card-sorting test (WCST), a test that measures attention and executive function, following sleep deprivation [36].

Correlations between scores in the widely used ESS and olfaction impairment were not significant. This indicates that testing is influenced by momentary sleepiness (KSS, SSS) rather than by general sleepiness within the last four weeks as evaluated by the ESS. This is supported by the findings of others that show a slight decrease in olfactory performance after sleep deprivation and increase of the SSS score [26]. Our patients did not undergo acute sleep deprivation and were probably less sleepy then the patients of Killgore and McBride.

In contrast to previous studies, we could not confirm decreased olfaction in patients with NC [8-10]. The largest and most recent study on the subject [10] reported mild-to-moderate olfactory deficits in about $24 \%$ of 130 narcoleptic patients (14\% in healthy controls) when compared to normative data. However, this finding was observed only in one of the two centers of the study, i.e. the Italian one, where only olfactory identification was tested by using the brief smell identification test (B-SIT). Testing in the French center was performed using the whole Sniffin'Sticks set, including olfactory threshold, discrimination, and identification. In fact, only discrimination testing (hence only one subtest composing the TDI score, which was used for comparison to normative data) produced significant differences between patients and control subjects. In other words, a higher prevalence of a mild olfactory identification deficit in NC was found in the Italian center, while a mild olfactory discrimination deficit was found in the French center using a different test.

Different factors can explain the normal olfactory results that we found for NC patients. First, we report here on a small sample size. Second, as shown in the study cited above [10], hyposmia might be present in NC to a much lower extent than initially supposed. Third, it is 
possible that NC patients present hyposmia only in relation to momentary EDS, making it harder to detect. This hypothesis is supported by two findings in our study: subjects that are sleepy at the time of testing tend to produce worse results, and untreated NC patients tend to produce worse results. If we follow this hypothesis we must note that, contrary to expectations, the NC patients in our study presented normal momentary sleepiness as well as normal olfaction.

Limitations of the present study include the relatively small sample groups and an imperfect age and gender matching of control subjects. In addition, it must be noted that our results for olfactory threshold testing with Sniffin'Sticks generally produced slightly lower scores than previously published normative data [37]. These scores were nevertheless coherent between groups and corroborated by the presence of an own control group on one side, clear confirmation of results such as impaired olfaction in PD and decreased olfaction with older age on the other side.

In summary we were not able to confirm the previously reported decreased olfaction in patients with NC, but our findings suggest that sleepiness is an important confounding factor that impairs olfaction testing.

\section{Disclosure Statement}

There are no conflicts of interest regarding the publication of this article.

\section{References}

1 Müller A, Müngersdorf $M$, Reichmann $H$, Strehle G, Hummel T: Olfactory function in Parkinsonian syndromes. J Clin Neurosci 2002;9:521-524.

2 Schenck CH, Mahowald MW: REM sleep parasomnias. Neurol Clin 1996;14:697-720.

3 Postuma RB, Montplaisir J: Predicting Parkinson's disease - why, when, and how? Parkinsonism Relat Disord 2009;15(suppl 3): S105-S109.

4 Fantini ML, Postuma RB, Montplaisir J, Ferini-Strambi L: Olfactory deficit in idiopathic rapid eye movements sleep behavior disorder. Brain Res Bull 2006;70:386-390.

5 Stiasny-Kolster K, Doerr Y, Möller JC, Höffken H, Behr TM, Oertel WH, Mayer G: Combination of 'idiopathic' REM sleep behaviour disorder and olfactory dysfunction as possible indicator for alpha-synucleinopathy demonstrated by dopamine transporter FP-CIT-SPECT. Brain 2005;128:126-137.

6 Braak H, Rüb U, Del Tredici K: Involvement of precerebellar nuclei in multiple system atrophy. Neuropathol Appl Neurobiol 2003;29: 60-76.

7 Braak H, Del Tredici K, Rüb U, de Vos RA, Jansen Steur EN, Braak E: Staging of brain pathology related to sporadic Parkinson's disease. Neurobiol Aging 2003;24:197-211.

8 Stiasny-Kolster K, Clever SC, Möller JC, Oertel WH, Mayer G: Olfactory dysfunction in patients with narcolepsy with and without REM sleep behaviour disorder. Brain 2007; 130:442-449.

9 Buskova J, Klaschka J, Sonka K, Nevsimalova S: Olfactory dysfunction in narcolepsy with and without cataplexy. Sleep Med 2010;11: 558-561.
10 Bayard S, Plazzi G, Poli F, Serra L, Ferri R, Dauvilliers Y: Olfactory dysfunction in narcolepsy with cataplexy. Sleep Med 2010;11: 876-881.

11 Bassetti C, Aldrich MS: Narcolepsy. Neurol Clin 1996;14:545-571. Review.

12 Nishino S, Ripley B, Overeem S, Lammers GJ, Mignot E: Hypocretin (orexin) deficiency in human narcolepsy. Lancet 2000;355: 39-40.

13 Ripley B, Overeem S, Fujiki N, Nevsimalova S, Uchino M, Yesavage J, Di Monte D, Dohi K, Melberg A, Lammers GJ, Nishida Y, Roelandse FW, Hungs M, Mignot E, Nishino S: CSF hypocretin/orexin levels in narcolepsy and other neurological conditions. Neurology 2001;57:2253-2258.

14 Mignot E, Lammers GJ, Ripley B, Okun M, Nevsimalova S, Overeem S, Vankova J, Black J, Harsh J, Bassetti C, Schrader H, Nishino S: The role of cerebrospinal fluid hypocretin measurement in the diagnosis of narcolepsy and other hypersomnias. Arch Neurol 2002; 59:1553-1562.

15 Saper CB: Staying awake for dinner: hypothalamic integration of sleep, feeding, and circadian rhythms. Prog Brain Res 2006;153: 243-252.

16 Caillol M, Aïoun J, Baly C, Persuy MA, Salesse R: Localization of orexins and their receptors in the rat olfactory system: possible modulation of olfactory perception by a neuropeptide synthetized centrally or locally. Brain Res 2003;960:48-61.

17 Julliard AK, Chaput MA, Apelbaum A, Aimé P, Mahfouz M, Duchamp-Viret P: Changes in rat olfactory detection performance induced by orexin and leptin mimicking fasting and satiation. Behav Brain Res 2007;183: 123-129.
18 Shibata M, Mondal MS, Date Y, Nakazato M, Suzuki H, Ueta Y: Distribution of orexinscontaining fibers and contents of orexins in the rat olfactory bulb. Neurosci Res 2008;61: 99-105.

19 Baier PC, Weinhold SL, Huth V, Gottwald B, Ferstl R, Hinze-Selch D: Olfactory dysfunction in patients with narcolepsy with cataplexy is restored by intranasal Orexin A (hypocretin-1). Brain 2008;131:2734-2741.

20 Thannickal TC, Lai YY, Siegel JM: Hypocretin (orexin) cell loss in Parkinson's disease. Brain 2007;130:1586-1595.

21 Fronczek R, Overeem S, Lee SY, Hegeman IM, van Pelt J, van Duinen SG, Lammers GJ, Swaab DF: Hypocretin (orexin) loss and sleep disturbances in Parkinson's disease. Brain 2008;131:e88.

22 Cervenka S, Pålhagen SE, Comley RA, Panagiotidis G, Cselényi Z, Matthews JC, Lai RY, Halldin C, Farde L: Support for dopaminergic hypoactivity in restless legs syndrome: a PET study on $\mathrm{D}_{2}$-receptor binding. Brain 2006;129:2017-2028.

23 Wetter TC, Eisensehr I, Trenkwalder C: Functional neuroimaging studies in restless legs syndrome. Sleep Med 2004;5:401-406.

24 Adler CH, Gwinn KA, Newman S: Olfactory function in restless legs syndrome. Mov Disord 1998;13:563-565.

25 McKinnon J, Evidente V, Driver-Dunckley E, Premkumar A, Hentz J, Shill H, Sabbagh $\mathrm{M}$, Caviness J, Connor D, Adler C: Olfaction in the elderly: a cross-sectional analysis comparing Parkinson's disease with controls and other disorders. Int J Neurosci 2010;120:3639. 
26 Killgore WD, McBride SA: Odor identification accuracy declines following $24 \mathrm{~h}$ of sleep deprivation. J Sleep Res 2006;15:111116.

27 Nordin S, Lötsch J, Murphy C, Hummel T, Kobal G: Circadian rhythm and desensitization in chemosensory event-related potentials in response to odorous and painful stimuli. Psychophysiology 2003;40:612619.

28 Stuck BA, Stieber K, Frey S, Freiburg C, Hörmann K, Maurer JT, Hummel T: Arousal responses to olfactory or trigeminal stimulation during sleep. Sleep 2007;30:506510.

29 Carskadon MA, Herz RS: Minimal olfactory perception during sleep: why odor alarms will not work for humans. Sleep 2004;27: 402-405.
30 Gibb WR, Lees AJ: The relevance of the Lewy body to the pathogenesis of idiopathic Parkinson's disease. J Neurol Neurosurg Psychiatry 1988;51:745-752.

31 American Academy of Sleep Medicine: International Classification of Sleep Disorders, ed 2. Diagnostic and Coding Manual. Westchester, American Academy of Sleep Medicine, 2005.

32 Brämerson A, Johansson L, Ek L, Nordin S, Bende M: Prevalence of olfactory dysfunction: the skövde population-based study. Laryngoscope 2004;114:733-737.

33 Akerstedt T, Gillberg M: Subjective and objective sleepiness in the active individual. Int J Neurosci 1990;52:29-37.
34 Hoddes E, Zarcone V, Smythe H, Phillips R, Dement WC: Quantification of sleepiness: a new approach. Psychophysiology 1973;10: 431-436.

35 Mackay-Sim A, Grant L, Owen C, Chant D, Silburn P: Australian norms for a quantitative olfactory function test. J Clin Neurosci 2004;11:874-879.

36 Killgore WD, Killgore DB, Grugle NL, Balkin TJ: Odor identification ability predicts executive function deficits following sleep deprivation. Int J Neurosci 2010;120: 328-334.

37 Hummel T, Sekinger B, Wolf SR, Pauli E, Kobal G: 'Sniffin'Sticks': olfactory performance assessed by the combined testing of odor identification, odor discrimination and olfactory threshold. Chem Senses 1997;22:3952. 